\title{
PERERAPAN MODEL PEMBELAJARAN KOOPERATIF TEAM ASSISTED INDIVIDUALIZATION DENGAN PENDEKATAN KONTEKSTUAL UNTUK MENINGKATKAN HASIL BELAJAR MATEMATIKA
}

\author{
Fina Lailati \\ Universitas PGRI Ronggolawe (UNIROW), Jl. Manunggal No.61, Tuban 62381, Indonesia \\ Email: lailatifina19@gmail.com
}

\begin{abstract}
Abstrak
Penelitian ini dilatarbelakangi oleh rendahnya hasil belajar matematika siswa kelas VII F SMP Negeri 5 Tuban pada bidang studi matematika. Salah satu penyebabnya adalah masih dilaksanakannya pembelajaran yang berpusat oleh guru, sehingga siswa menjadi pasif dan kurang berpartisipasi dalam tugas kelompok pada proses pembelajaran, hal ini mengakibatkan rendahnya hasil belajar siswa. Berdasarkan masalah tersebut, maka dibutuhkan suatu model pembelajaran sebagai alternatif untuk mengatasi masalah tersebut yaitu melalui model pembelajaran kooperatif Teaam Assisted Individualization dengan pendekatan kontesktual. Penelitian ini bertujuan untuk 1). Mendeskripsikan peningkatan hasil belajar matematika siswa setelah diterapkan model pembelajaran kooperatif Team Assisted Individualization dengan pendekatan kontekstual. 2). Untuk mendesripsikan respon siswa setelah diterapkan model pembelajaran kooperatif tipe Team Assisted Individualization dengan pendekatan kontesktual. Penelitian tindakan kelas (PTK) ini dilaksanakan dikelas VII F SMP N 5 Tuban Tahun Ajaran 2017/2018. Hasil penelitian ini dapat disimpulkan bahwa hasil belajar siklus I, siklus II dan siklus III, mengalami peningkatan. Hasil belajar pada siklus I dikatakan meningkat adanya dengan nilai rata-rata hasil belajar siswa pada siklus I adalah 76,40, siklus II 82,30 dan pada siklus III 94,40. Jadi dapat disimpulkan bahawa penerapan model pembelajaran kooperatif Team Assisted Individualization dengan pendekatan kontekstual dapat meningkatkan hasil belajar matematika siswa kelas VII F SMP N 5 Tuban tahun ajaran 2017/2018.
\end{abstract}

Kata kunci: Kooperatif Team Assisted Individualization, Pendekatan Kontekstual, Respon, Hasil Belajar

\begin{abstract}
This research is motivated by the low learning outcomes of mathematics students of SMP N 5 Tuban in the field of mathematics study. One of the causes is still the implementation of teacher-centered learning, so students become passive and less participate in grouping on learning, this resulted in low student learning outcomes. Based on the problem, then needed a model of learning as an alternative to overcome the problem that is through cooperative learning model of Teaam Assisted Individualization with conteskual approach. This study aims to 1). Describe the improvement of students' mathematics learning outcomes after applying cooperative learning model Team Assisted Individualization with contextual approach. 2). To describe student response after applied cooperative learning model of Team Assisted Individualization type with contesktual approach. This study was conducted in class VII F SMP N 5 Tuban Year of Education 2017/2018. This research type is class action research (PTK). The results of this study can be concluded that the results of learning cycle I, cycle II and cycle II, increased. The learning outcomes in cycle I are said to increase with the completeness of classical learning in cycle I is $80.00 \%$ cycle II $92.30 \%$ and in $100 \%$ III cycle so it can be concluded that the implementation of cooperative learning model Team Assisted Individualization with contextual approach can improve learning outcomes mathematics students of class VII F SMP N 5 Tuban academic year 2017/2018.
\end{abstract}

Keywords: Cooperative Learning Model Team Assisted Individualization, Contextual, Response, Learning Outcomes

\section{PENDAHULUAN}

Pendidikan merupakan salah satu faktor yang penting dalam kemajuan suatu bangsa. Pendidikan yang baik akan membawa pengaruh positif pada semua aspek. Permasalahan yang kini 
dihadapi didalam dunia pendidikan adalah bagaimana meningkatkan kualitas pendidikan yang umumnya berkaitan dengan tinggi rendahnya hasil belajar yang diperoleh siswa (Vidiyanto, $2015: 1$ ). Hal ini disebabkan banyak siswa yang mengalami masalah baik secara komprehensif maupun secara persial dalam matematika. Siswa cenderung mengalami kesulitan dalam mengaplikasikan matematika kedalam situasi kehidupan real dan yang menyebabkan sulitnya matematika bagi siswa adalah mereka belum memahami asal rumus atau konsep matematika diperoleh.

Berdasarkan data kemendikbud kabupaten Tuban nilai rata-rata hasil Ujian Nasional SMP pada tahun 2017 adalah Bahasa Indonesia 64,32, Bahasa Inggris 50,18, IPA 52,19, Matematika 50,31. Rata-rata ini menunjukkan bahwa nilai matematika Ujian Nasional termasuk rendah dibanding mata pelajaran lain. Rendahnya nilai matematika bisa jadi karena proses pembelajaran yang masih berpusat pada guru, guru masih menggunakan model pembelajaran konvensional, siswa kurang bisa mengkaitkan materi dengan kehidupan sehari-hari sehingga mereka mengalami kesulitan dalam memahami materi, atau kurangnya pemahaman konsep matematika siswa.

Berdasarkan hasil observasi di kelas VII F SMP 5 Tuban pada bulan februari 2018 dan wawancara dengan Bu Dra. Esti Khomariyah selaku guru matematika kelas VII-F SMP N 5 pada bulan februari 2018 Tuban diperoleh bahwa dalam pembelajaran ada kelebihan dan kelemahan. Untuk kelemahannya yaitu kurangnya pendekatan dan metode dalam pembelajaran, tidak hanya menerapkan materi saja tetapi butuh pendekatan dan metode yang cocok untuk diterapkan pada siswa. Dalam menerangkan pembelajaran pada siswa juga tidak bisa secara cepat maupun santai, tetapi harus jelas agar siswa lebih dan cepat memahami apa yang disampaikan oleh guru. Selain itu, pembelajaran di kelas juga masih menggunakan pemblajaran konvensiaonal yaitu pembelajaran yang berpusat pada guru. Kelemahan lain dari siswa kelas VII-F ini masih bersifat kekanak-kanakan yaitu masih manja dan mancari perhatian dari guru karena masih terbawa sifat dari tingkatan sekolah sebelumnya. Hal tersebut tidak mendorong siswa menjadi aktif dan mandiri.

Dari permasalahan tersebut peneliti mencoba menerapkan model atau metode pembelajaran yang akan mengaktifkan siswa dalam kegiatan pembelajaran yang menghidupkan interaksi antara siswa dengan guru, siswa dengan siswa, serta keterlibatan siswa dalam proses pembelajaran sehingga dapat meningkatkan hasil belajar siswa. Salah satunya melalui penerapan model pembelajaran kooperartif Team Assisted Individualization dengan pendekatan kontekstual. Sehingga dengan menerapkan model seperti itu diharapkan tidak ada siswa yang mudah bosan dalam pembelajaran.

Menurut Robert Slavin(1984), Team Assisted Individualization(TAI) merupakan sebuah program pedagogik yang berusaha mengadaptasikan pembelajaran dengan perbedaan individu siswa secara akademik. Pengembangan TAI dapat mendukung praktik-praktik ruang kelas, seperti pengelompokan siswa, pengajaran terprogram. Tujuan TAI adalah untuk meminimalisasikan pengajaran individu yang terbukti kurang efektif, selain juga ditunjukan untuk meningkatkan pengetahuan, kemampuan serta memotivasi siswa dalam belajar kelompok. 
Ada beberapa manfaat TAI yang memungkinkan memenuhi kriteria pembelajaran efektif diantaranya adalah 1) meminimalisasikan keterlibatan guru dalam pemeriksaan dan pengelolaan rutin, 2) melibatkan guru untuk mengajar kelompok-kelompok kecil yang heterogrn, 3) memudahkan siswa untuk melaksanakannya karena teknik operasional yang cukup sederhana, 4) memotivasi siswa untuk mempelajari materi-materi ayng diberikan dengan cepat dan akurat tanpa jalan pintas, 5) memungkinkan siswa untuk bekerja dengan siswa-siswa lain yang berbeda sehingga tercipta sikap positif diantara mereka (dalam Huda 2013 : 200).

Sedangkan menurut Eline B. Johnson kontekstual adalah sebuah proses pendidikan yang bertujuan menolong para siswa melihat makna didalam materi akademik yang mereka pelajari dengan cara menghubungan subjek-subjek akademik dengan konteks dalam keadaan pribadi, sosial dan budaya mereka.

Sedangkan pendekatan kontektual adalah suatu proses yang holistik dan bertujuan memotivasi siswa unruk memahami makna materi pelajaran yang dipelajarinya dengan mengkaitkan materi tersebut dengan konteks kehidupan sehari-hari (konteks pribadi, sosial dan kalturu), sehingga siswa memiliki pengetahuan dan keterampilan yang dinamis dan fleksibel unruk mengkontruksi sendiri secara aktif pemahamannnya.

Selanjutnya penerapaan kontekstual dalam proses pembelajaran menekankan tiga hal. Pertama, kontekstual menekankan kepada proses keterlibatan siswa untuk menemukan materi pelajaran. Artinya, proses belajar diorientasikan pada proses pengalaman secara langsung. Menurut Johnson (dalam Suyadi, 2013:82) proses belajar dalam kontekstual tidak mengharapkan agar siswa hanya menerima pelajaran, tetapi proses mencari dan menemukan sendiri pelajaran tersebut. Kedua, kontekstual mendorong agar siswa dapat menemukan hubungan antara materi yang dipelajari dengan realitasi kehidupan nyata. Artinya, siswa dituntut dapat menangkap hubungan antara pengalaman belajar disekolah dengan kehidupan nyata. Ketiga, kontekstual mendorong siswa untuk dapat menerapkannya dalam kehidupan sehari-hari. Artinya, kontektual bukan hanya mengharpkan siswa dapat memahami materi yang dipelajari, tetapi lebih kepada aktualisasi dan kontekstual materi pelajaran dalam kehidupan sehari-hari.

Dari uraikan di atas, tujuan dari penelitian ini adalah 1). Untuk mendeskripsikan peningkatan hasil belajar matematika siswa setelah diterapkan model pembelajaran kooperatif Team Assisted Individualization dengan pendekatan kontekstual. 2). Untuk mendesripsikan respon siswa setelah diterapkan model pembelajaran kooperatif tipe Team Assisted Individualization dengan pendekatan kontesktual

\section{METODE PENELITIAN}

\section{Rancangan Penelitian}

Jenis penelitian yang dilakukan adalah penelitian tindakan kelas (PTK) atau Classroom Action Research (CAR). Penelitian bercirikan kepada perbaikan terus menerus sampai pada 
kepuasan peneliti untuk menjadikan tolak ukur keberhasilan. Untuk setiap siklus terdiri atas empat tahapan yaitu perencanaan, pelaksanaan tindakan, pengamatan, dan refleksi.

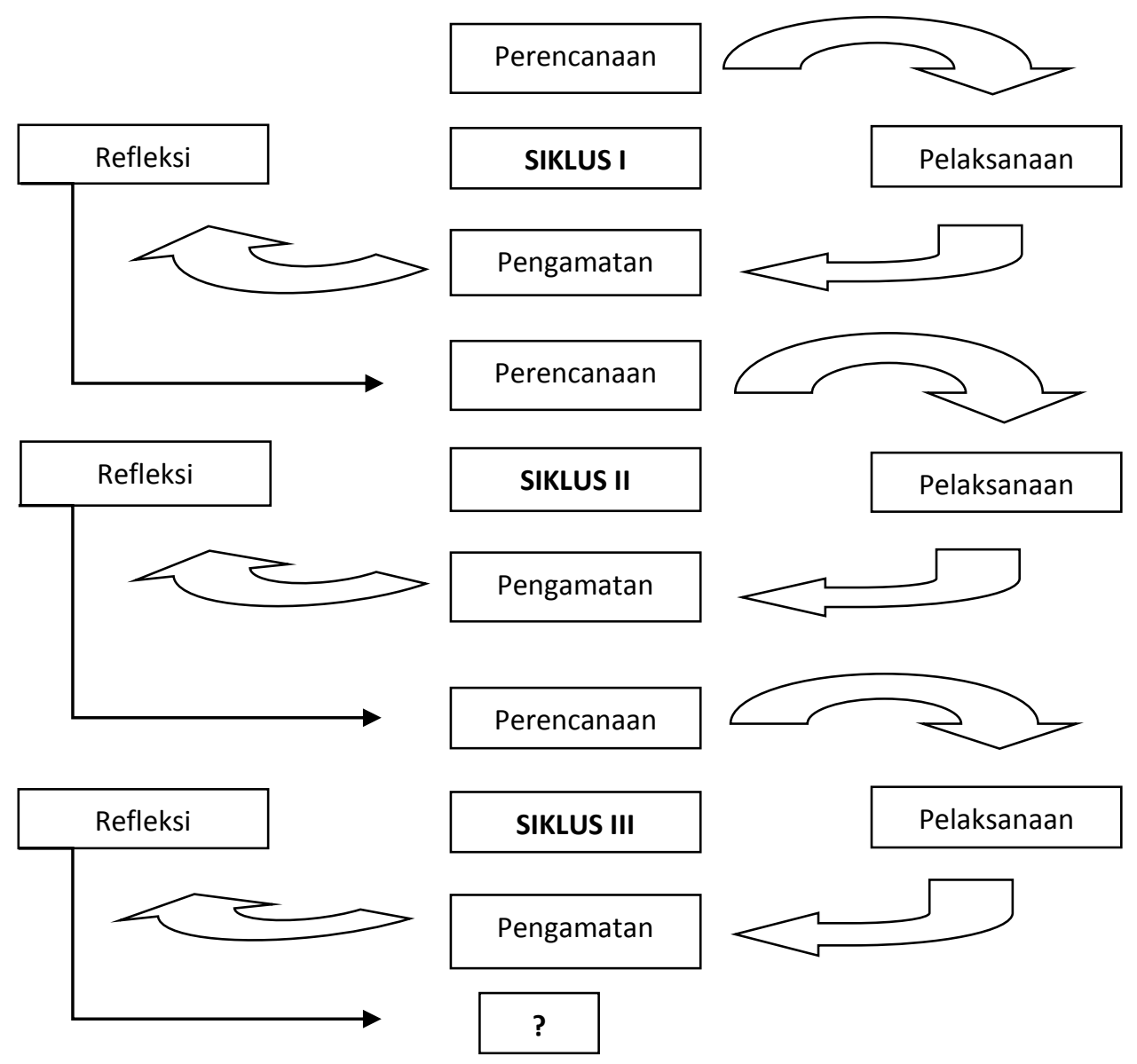

Gambar 1. Siklus Penelitian Tindakan Kelas (Arikunto, 2013:137)

Subjek penelitian adalah kelas VII F SMP N 5 Tuban. Jenis data dalam penelitian ini adalah data kuantitatif, yaitu berupa skor nilai tes hasil belajar matematika dan menggunakan sumber data primer yaitu suatu data yang diperoleh dari sumbernya langsung. Instrumen tes yang digunakan dalam penelitian ini adalah test hasil belajar matematika.

Tes ini diberikan kepada siswa berupa tes tulis sebelum dan sesudah pembelajaran untuk mengetahui kemampuan siswa dan hasil belajar siswa dengan menggunakan model pembelajaran Team Assisted Individualization dengan pendekatan kontekstual dalam pokok bahasan bangun ruang segiempat(persegi dan persegi panjang, trapesium dan jajargenjang, belahketupat dan layang-layang). Pada tiap siklus dalam bentuk essay yang terdiri dari 4 buah soal kelompok dan 3 soal evaluasi dengan skor tertinggi masing-maisng 100, dimana hasil nilai lembar evaluasi tersebut dianalisis untuk mendapatkan data berupa rata-rata nilai yang diperoleh siswa pada setiap siklusnya. 
Angket atau koesioner digunakan untuk memperoleh data tentang respon siswa setelah mengikuti pembelajaran dengan model pembelajaran kooperatif tipe Team Assisted Individualization dengan pendekataan kontektual yaitu dilakukan pada akhir pertemuan. Dalam pemberian angket ini, seluruh siswa diberikan informasi untuk menjawab setiap pertanyaan sesuai dengan apa yang didapat dan dirasakan tanpa mempengaruhi hasil penilaian LKS.

Adapun instrumen yang digunakan dalam penelitian ini yaitu:

\section{Analisis Data Tes Hasil Belajar}

Untuk menganalisis data hasil belajar siswa memakai pedoman kurikulum 2013, standar ketuntasan hasil belajar siswa ditenrukan oleh sekolah yang bersangkutan dalam hal ini adalah SMP N 5 Tuban menetapkan bahwa ketuntasan maksimal untuk pelajaran matematika adalah 75, sedangkan siswa dikatakan tuntas belajar secara individu jika telah mendapat nilai $\geq 75$, sedangkan presentase ketuntasan belajar siswa secara klasikal dikatakan tuntas belajar jika mencapai ketuntasan 85 yaitu kategori efektif.

Presentase ketuntasan belajar siswa adalah sebagai berikut:

a. Ketuntasan individu

perhitungan presentase ketuntasan belajar secara individu adalah sebagai berikut:

$$
\mathrm{KBI}=\frac{\text { skor yang dicapai siswa }}{\text { skor maksimal }} \times 100 \%
$$

Keterangan : KBI = Ketuntasan belajar individu

b. Ketuntasan belajar klasikal

$$
\mathrm{KBK}=\frac{\text { Banyaknya siswa yang tuntas }}{\text { Banyaknya siswa }} \times 100 \%
$$

Keterangan : KBK = Ketuntasan belajar klasikal

Adapun kriteria hasil belajar kelas siswa

\begin{tabular}{lcc}
\hline No & $\begin{array}{c}\text { Kriteria Hasil Belajar Kelas Dalam } \\
\text { pembelajaan }\end{array}$ & Kriteria Nilai \\
\hline 1. & Sangat Tidak Efektif & $65 \%$ \\
\hline 2. & Tidak Efektif & $65-74 \%$ \\
\hline 3. & Cukup Efektf & $75-84 \%$ \\
\hline 4. & Efektif & $85-94 \%$ \\
\hline 5. & Sangat Efektif & $95-100 \%$ \\
\hline
\end{tabular}

2. Analisis data respon siswa

Data respon digunakan untuk menganalisa data tentang respon siswa yang didasarkan pada presentase. Presentase respon siswa didefinisikan sebagai frekuensi siswa yang memilih 
jawaban dibagi dengan banyaknya siswa dikali 100\%. Respon siswa dikategorikan positif jika siswa yang merespon positif lebih besar dari $75 \%$

Data diperoleh dengan rumus:

$$
P_{r}=\frac{B}{n} \times 100 \%
$$

Warli (dalam Huda, 2017:48)

Keterangan :

$\mathrm{P}_{\mathrm{r}}$ : Presentase banyak siswa yang memberikan respon positif terhadap kategori yang dinyatakan dalam angket

B : Banyak siswa yang memberikan respon positif terhadap kategori yang dinyatakan dalam angket

$\mathrm{n}$ : Banyak siswa yang menjadi responden

Respon siswa dianggap positif terhadap pembelajaran jika presentase respon yang bersifat positif diperoleh lebih dari $75 \%$

\section{HASIL PENELITIAN DAN PEMBAHASAN}

Setelah peneliti melakukan penelitian, peneliti dapat mendiskripsikan hasil penelitian sebagai berikut:

\section{Hasil Belajar}

Data hasil belajar siswa selama pelaksanaan pembelajaran siklus I, II dan III dapat dilihat dari tabel 1

Tabel 1 Perbandingan Hasil Belajar Siswa Siklus I, Siklus II dan Siklus III

\begin{tabular}{lccc}
\hline \multicolumn{1}{c}{ Hasil Belajar Siswa } & Siklus I & Siklus II & Siklus III \\
Nilai Terendah & 20 & 40 & 50 \\
Nilai Tertinggi & 80 & 87,5 & 100 \\
Rata-rata hasil belajar siswa & 76,4 & 82,31 & 94,4 \\
Ketuntasan hasil belajar & $80 \%$ & $92,31 \%$ & $100 \%$ \\
klasikal & & & \\
\hline
\end{tabular}




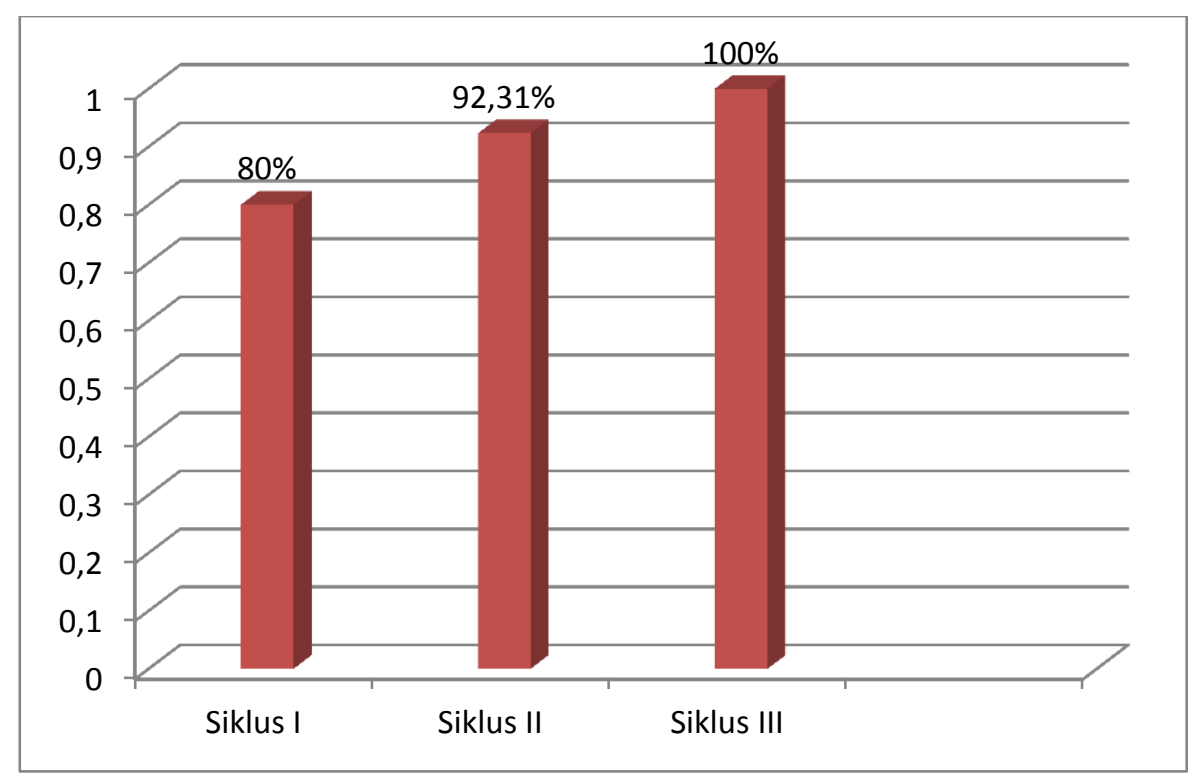

Gambar 4.2 grafik Ketuntasan hasil belajar klasikal

\section{Hasil Angket Respon}

Setelah dilakukan kegiatan belajar mengajar maka peneliti membagikan angket kepada siswa dimana angket tersebut berisi tentang pertanyaan mengenai kegiatan belajar yang telah berlangsung pada siklus I, siklus II dan siklus III.

Berikut ini hasil angket respon siswa:

\begin{tabular}{|c|c|c|c|}
\hline \multirow[t]{2}{*}{ No } & \multirow[t]{2}{*}{ Pertanyaan } & \multicolumn{2}{|c|}{ Respon } \\
\hline & & Setuju & Tidak Setuju \\
\hline \multirow[t]{4}{*}{1.} & $\begin{array}{l}\text { Bagaimana pendapat anda tentang komponen kegiatan belajar } \\
\text { mengajar di bawah ini, apakah menyenangkan? }\end{array}$ & & \\
\hline & a. Suasana kelas & $85,19 \%$ & $14,81 \%$ \\
\hline & b. Cara belajar & $92,59 \%$ & $7,41 \%$ \\
\hline & c. $\quad$ Cara guru mengajar & $92,59 \%$ & $7,41 \%$ \\
\hline 2. & $\begin{array}{l}\text { Model Pembelajaran Team Assisted Individualization dengan } \\
\text { pendekatan kontektual dalam pembelajaran matematika mendorong } \\
\text { saya untuk menemukan ide-ide baru }\end{array}$ & $88,89 \%$ & $11,11 \%$ \\
\hline 3. & $\begin{array}{l}\text { Saya merasa tertekan dalam pembelajaran matematika dengan } \\
\text { model pembelajaran Team Assisted Individualization dengan } \\
\text { pendekatan kontektual }\end{array}$ & $14,81 \%$ & $85,19 \%$ \\
\hline 4. & $\begin{array}{l}\text { Pembelajaran matematika dengan model pembelajaran Team } \\
\text { Assisted Individualization dengan pendekatan kontektual membuat } \\
\text { saya lebih merasa termotivasi }\end{array}$ & $88,89 \%$ & $11,11 \%$ \\
\hline 5. & $\begin{array}{l}\text { Saya kurang termotivasi apabila dalam pembelajaran matematika } \\
\text { menggunakan Team Assisted Individualization dengan pendekatan } \\
\text { kontektual }\end{array}$ & $14,81 \%$ & $85,19 \%$ \\
\hline 6. & $\begin{array}{l}\text { Dengan pembelajaran Team Assisted Individualization, saya } \\
\text { menjadi lebih aktif dalam kegiatan belajar di kelas }\end{array}$ & $85,19 \%$ & $14,81 \%$ \\
\hline 7. & $\begin{array}{l}\text { Model pembelajaran Team Assisted Individualization dengan } \\
\text { pendekatan kontektual dalam pembelajaran matematika } \\
\text { membuang-buang waktu belajar saya }\end{array}$ & $3,70 \%$ & $96,30 \%$ \\
\hline 8. & $\begin{array}{l}\text { Bagaimana komentarmu tentang Lembar Kerja Siswa yang } \\
\text { diberikan, apakah mudah dipahami ? }\end{array}$ & $85,19 \%$ & $14,81 \%$ \\
\hline
\end{tabular}




\begin{tabular}{c|l|c|c}
\hline No & \multicolumn{1}{|c}{ Pertanyaan } & \multicolumn{2}{|c}{ Respon } \\
\cline { 3 - 3 } & \multicolumn{1}{|c}{ Setuju } & Tidak Setuju \\
\hline 9. & $\begin{array}{l}\text { Apakah Lembar Kerja Siswa yang digunakan dalam pembelajaran } \\
\text { ini membimbing kamu dalam belajar? }\end{array}$ & $96,30 \%$ & $3,70 \%$ \\
\hline 10. & $\begin{array}{l}\text { Apakah kamu berminat untuk mengikuti pembelajaran berikutnya } \\
\text { seperti pembelajaran ini ? }\end{array}$ & $81,48 \%$ & $18,52 \%$ \\
\hline
\end{tabular}

\section{KESIMPULAN}

Hasil belajar matematika siswa selama mengikuti pembelajaran kooperatif Team Assisted Individualization dengan pendekatan kontektual pada pokok bahasan bangun datar segiempat pada kelas VII-F SMP N 5 Tuban tahun pelajaran 2017/2018 mengalami peningkatan. Hal ini dapat ditunjukan dari hasil belajar siswa siklus I memperoleh nilai rata- rata 76,4, pada siklus II dengan rata- rata 82,31 dari siklus I ke siklus II mengalami peningkatan sebesar 5,91, pada siklus III memperoleh hasil rata- rata 94,4 dari siklus II ke siklus III mengalami peningkatan sebesar 12,09.

Hasil respon siswa terhadap pembelajaran matematika melalui model pembelajaran kooperatif Team Assisted Individualization dengan pendekatan kontekstual sangat positif. Dimana dianalisis bahwa 80 $\%$ dari jawaban siswa memberikan respon positif.

\section{REFERENCES}

Agus, Suprijono. 2009. Cooperative Learning Teori \& Aplikasi PAIKEM. https://slam3tsubagyo.files.wordpress.com/2011/06/kumpulanmetodepembelajaranpaikemteoridanaplikasi.pdfYogyakarta : Pustaka Pelajar. Diakses pada tanggal 20 Maret2018

Arifin, Zaenal. 2009. Membangun Kompetensi Pedagogis Guru Matematika. Surabaya : Lentera Cendekia

Arifin, Zaenal. 2010. Evaluasi Pembelajaran. Bandung : PT Remaja Rosdakarya

Arikunto, Suharsimi. 2010. Prosedur Penelitian Suatu Pendekatan Praktik. Jakarta : Rinika Cipta

Arikunto, Suharsimi. 2013. Prosedur Penelitian. Jakarta : Reneka Cipta

Johnson, Elaine B.2002. Contextual Teaching \& Learning. Californa : Kaifa

Slavin, Robert E. 2005. Cooperatif Learning. London : Allymand Bacon

Suyadi. 2013. Strategi Pembelajaran pendidikan Karakter. Bandung : PT Remaja Rosdakarya Offiset 